\title{
Sclerostin and Vascular Pathophysiology
}

\author{
Antonino Catalano 1,2,*(D), Federica Bellone ${ }^{1,2}$, Nunziata Morabito ${ }^{1,2}$ and Francesco Corica 1,2 \\ 1 Department of Clinical and Experimental Medicine, University of Messina, 98125 Messina, Italy; \\ fbellone@unime.it (F.B.); nmorabito@unime.it (N.M.); coricaf@unime.it (F.C.) \\ 2 A.O.U. Policlinico "G.Martino", Via Consolare Valeria, 98125 Messina, Italy \\ * Correspondence: catalanoa@unime.it; Tel.: +39-090-221-3946; Fax: +39-090-221-7176
}

Received: 23 May 2020; Accepted: 3 July 2020; Published: 6 July 2020

\begin{abstract}
There is cumulating evidence for a contribution of Wnt signaling pathways in multiple processes involved in atherosclerosis and vascular aging. Wnt signaling plays a role in endothelial dysfunction, in the proliferation and migration of vascular smooth muscle cells (VSMCs) and intimal thickening. Moreover, it interferes with inflammation processes, monocyte adhesion and migration, as well as with foam cell formation and vascular calcification progression. Sclerostin is a negative regulator of the canonical Wnt signaling pathway and, accordingly, the consequence of increased sclerostin availability can be disruption of the Wnt signalling cascade. Sclerostin is becoming a marker for clinical and subclinical vascular diseases and several lines of evidence illustrate its role in the pathophysiology of the vascular system. Sclerostin levels increase with aging and persist higher in some diseases (e.g., diabetes, chronic kidney disease) that are known to precipitate atherosclerosis and enhance cardiovascular risk. Current knowledge on the association between sclerostin and vascular diseases is summarized in this review.
\end{abstract}

Keywords: sclerostin; Wnt; cardiovascular; atherosclerosis; aging; calcification; chronic kidney disease; diabetes mellitus

\section{Introduction}

Aging produces profound effects on the vasculature, and it is strictly associated with the development cardiovascular and cerebrovascular diseases, which are the most common causes of death among the elderly in developed countries [1]. The circulatory system may influence the local environment of tissues and organs. Therefore, age-induced functional and structural alterations of microcirculation play a role in the pathophysiology of a wide range of known age-related disorders, including cognitive impairment, sarcopenia and kidney or eye diseases [1,2].

Several aging mechanisms have been variously considered as contributing to the pathogenesis of both microvascular and macrovascular diseases such as oxidative stress, mitochondrial dysfunction, impaired resistance to molecular stressors, chronic low-grade inflammation, genomic instability, telomeric attrition and cellular senescence, epigenetic alterations, stem cell exhaustion and altered intercellular communication [3].

Since several age-related cardiovascular and cerebrovascular diseases arise from alterations in arterial function, or are worsened by arterial functional and phenotypic changes, elucidating the basic mechanisms underlying arterial aging seems to be a matter of interest.

In the last decades, signalling triggered by the Wnt family of secreted glycoproteins has emerged as one of the major mechanisms associated with a plethora of biological processes including embryonic and adult stem cell development, cell differentiation, proliferation, polarity and migration [4-7]. The term "Wnt" is a portmanteau word derivied from the blend of the name of the Wingless segment polarity gene in drosophila and that of its vertebrate homolog, known as integrated or int-1. These conserved signalling pathways begin with proteins transmitting to the cell through its surface receptors [5]. 
As emerged from loss- and gain-of-function experimental models, Wnt signalling might contribute to vascular development and homeostasis [8].

In this review, we first illustrate the function of Wnt signalling and, secondly, we highlight the role of this pathway in vascular pathophysiology. The available evidence from in vitro and in vivo studies about Wnt proteins, receptors and antagonists, with a special focus on sclerostin, are shown below.

\section{Wnt Signaling Pathways: A Synopsis}

Wnt proteins are secreted glycoproteins that bind to the N-terminal extracellular cysteine-rich domain of the Frizzled (Fz) receptor family, which is characterized by a seven-transmembrane-span (Figure 1) [5-8]. In addition to the interaction between Wnt and the transmembrane Fz receptor, coreceptors are also necessary to promote Wnt signaling. Thus, the low-density lipoprotein-related protein 5/6 (LRP5/6) is required to mediate the canonical Wnt signal, forming a receptor complex after interaction with the Wnt protein [5]. The signal is transduced to the cytoplasmic phosphoprotein Dishevelled (Dsh/Dvl), which is able to directly interact with Fz. At this level of Dsh, the Wnt signal branches into at least three major cascades, i.e., the canonical pathway, the planar cell polarity (PCP) pathway and the Wnt/ $\mathrm{Ca}^{2+}$ route. The hallmark of the canonical Wnt pathway is represented by the translocation of the cytoplasmic protein $\beta$-catenin into the nucleus. In the canonical pathway, the activated receptor signals through Dsh and acts on a protein complex containing axin, glycogen synthase kinase $3 \beta(\mathrm{GSK} 3 \beta)$, casein kinase $1 \alpha(\mathrm{CK} 1 \alpha)$ and adenomatosis polyposis coli (APC) molecules. This complex, in the absence of Wnt ligands, promotes the ubiquitination and degradation of $\beta$-catenin [5,7]. Conversely, the binding of Wnt ligands to the transmembrane Fz receptor and LRP5/6 coreceptor triggers the inactivation of the degradation complex leading to a translocation of $\beta$-catenin to the nucleus where it interacts with the T cell factor (TCF)/lymphoid-enhancer binding factor (LEF) and activates the transcription of Wnt target genes such as c-Myc, cyclin D1 and PPAR $\delta$, which govern cell growth as well as cell proliferation and survival [5].

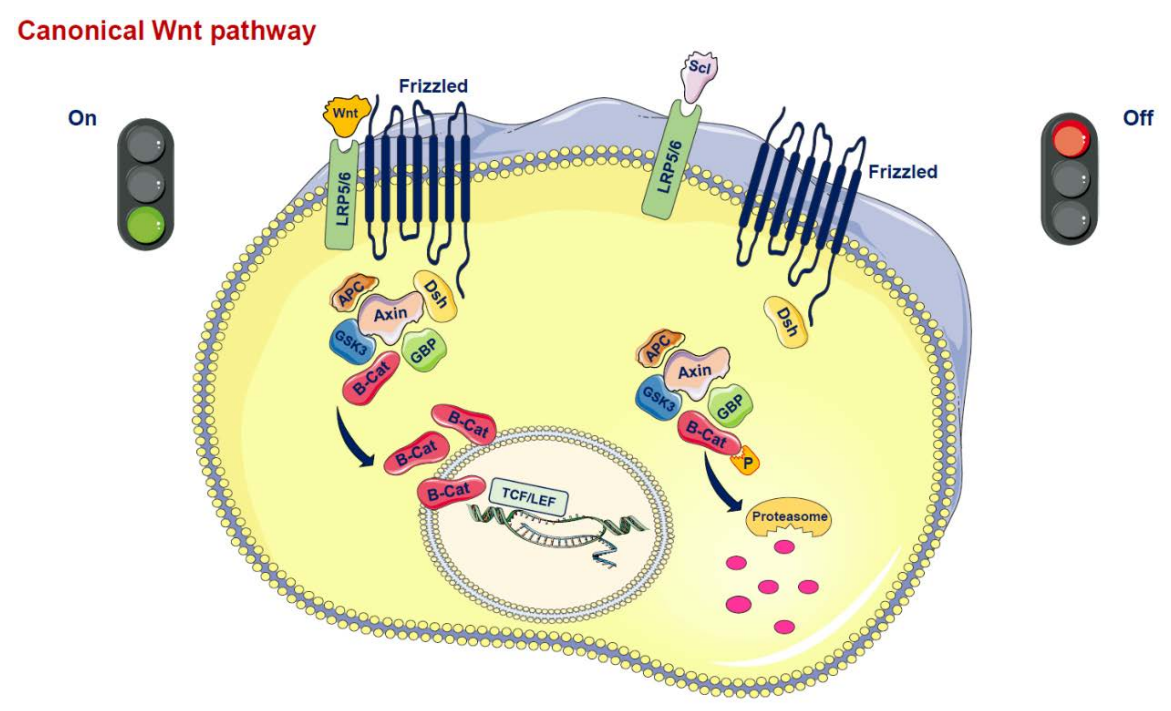

Figure 1. Canonical Wnt pathway. In the active state, Wnt ligands (Wnt) form a complex with the receptors low-density lipoprotein receptor-related protein 5 or 6 (LRP5/6) and Frizzled (Fz). Disheveled (Dsh) is then able to bind to Fz. Dsh forms a complex with glycogen synthase kinase 3ß (GSK3ß), GSK3 binding protein (GBP), axin and adenomatous polyposis coli (APC). This protects B-catenin from proteasomal degradation. $B$-catenin translocates into the nucleus and interacts with the T-cell factor/lymphoid enhancer factor (TCF/LEF) family of transcription factors to promote gene transcription. In the inactive state, inhibitors of this system, such as Sclerostin (SCL), prevent the formation of the Wnt-Fz-LRP5/6 complex. B-catenin is degraded by proteasomes after GSK3ß-mediated phosphorylation, so the signal is stopped. 
Beyond this canonical pathway involving $\beta$-catenin, two other noncanonical pathways have been described: the $\mathrm{Wnt} / \mathrm{Ca}^{2+}$ pathway, which affects cell adhesion and movement, and the noncanonical PCP, which mediates asymmetric cytoskeletal organization and the polarization of cells, all of which have been related to several human diseases [4-6].

As expected, the composite Wnt pathway is tightly regulated. A key level of its modulation occurs in the extracellular milieu due to a number of secreted Wnt antagonists including secreted frizzled related proteins (sFRPs) and the Wnt inhibitory factor- 1 (WIF1), which bond directly to Wnt molecules and alter their ability to bind to the Wnt receptor complex. Another signalling modulation occurs via the Dickkopf (DKK) family members and sclerostin, which inhibit the pathway by binding to LRP5/6 [5-9]. Furthermore, the canonical and noncanonical Wnt signalling pathways are closely connected and cross-regulate each other in a Wnt signaling network $[10,11]$.

\section{Atherosclerosis and Wnt Signaling}

Atherosclerosis is a multifactorial process during which circulating oxidized lipids accumulate in the subendothelial space and are subsequently internalized by resident macrophages, leading to the establishment of foam cells and finally of the atheromatic plaque core. As it is known, the development of atherosclerosis is associated with the migration and proliferation of vascular smooth muscle cells (VSMCs) and to endothelial activation, which are produced by multiple inflammatory pathways [12,13].

A consideration of Wnt signalling involvement in atherosclerosis was raised from certain clinical observations. In an Iranian family with early coronary artery disease, hypertension, hyperlipidemia and osteoporosis, a homozygous loss-of-function mutation R611C in the LRP6 gene was described in the affected subjects, along with an increased risk of carotid artery atherosclerosis in hypertensive subjects without hyperlipemia $[14,15]$. However, numerous study findings both from in vitro and in vivo investigations, as shown below, suggested contribution of Wnt signalling pathways to the vascular pathophysiology (Figure 2).

\section{Sclerostin in the vascular system}

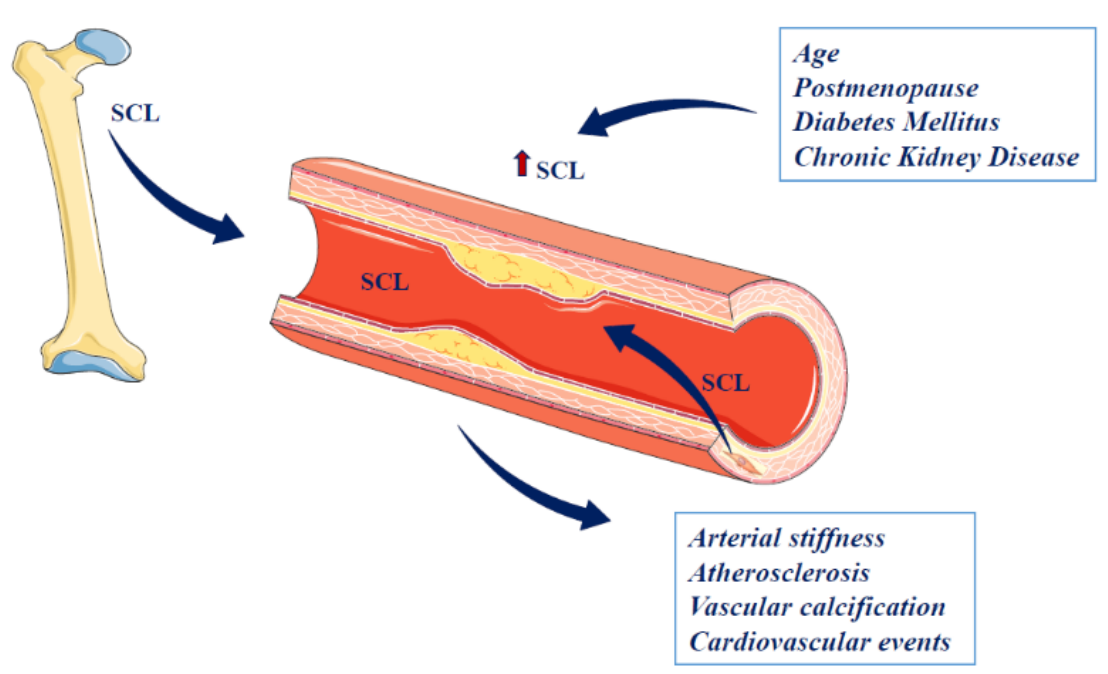

Figure 2. Sclerostin in the vascular system. SCL is produced by osteocytes at bone level and may drive the paracrine effect. SCL also spills over the circulation and may contribute to vascular pathophysiology (e.g., atherosclerosis, arterial stiffness and vascular calcification). SCL is also up-regulated in calcifying vascular smooth muscle cells at the vascular level. SCL = sclerostin. Arrows indicate the spill over of sclerostin from the sites where it is produced into circulation and the related factors or diseases associated with higher sclerostin circulating levels. 
Experimental Evidence of Wnt Pathway Involvement in the Atherosclerotic Process

Several researches exploring the pathophysiology of atherosclerosis focused on Wnt proteins as activators of the Fz receptor family (Table 1). High levels of Wnt5a have been detected in macrophage-rich areas of atherosclerotic plaques. Bacterial structures such as lipopolysaccharide (LPS) bind the Toll-like receptor 4 (TLR4), whose downstream signalling induces the expression of Wnt5a [16-19]. Wnt5a can promote the release of proinflammatory cytokines driving an inflammatory response. Contrariwise, Wnt3a, via the suppression of GSK3 $\beta$, shows an anti-inflammatory effect which in turn modulates NFKB-dependent gene transcription [20].

Kin et al. observed that Wnt5a induces cyclooxygenase- 2 expression and boosts the release of inflammatory cytokines. Particularly, they observed that a calcium ionophore enhances endothelial inflammation similarly, whereas calcium chelators and protein kinase $C$ inhibitors block the Wnt5a-induced activation, suggesting a role of the $\mathrm{Wnt} / \mathrm{Ca}^{2+} /$ protein kinase $\mathrm{C}$ pathway in endothelial inflammatory regulation [21]. Furthermore, it has been observed that the Wnt antagonist DKK-1 increased in atherosclerotic plaques and was involved in the atherosclerotic plaque inflammatory response. Augmented levels of DKK-1 have been detected in experimental (ApoE(-/-) mouse) atherosclerosis and, as with the human clinical scenario, in patients suffering from coronary artery disease or from carotid plaques, both systemically and locally, with high levels noticed, above all, in advanced and unstable disease states. Moreover, a role for platelet- and endothelial-derived DKK-1 in platelet-dependent endothelial activation has been proposed due to its promotion of an inflammatory cytokine enhanced release [22].

Borrell-Pages et al. investigated the role of LRP5 in macrophage differentiation and migration upon lipid loading. LRP5 is transcriptionally regulated by aggregated low density lipoprotein (agLDL), participating in lipid uptake and transformation of macrophages into foam cells, a critical step in atherosclerosis progression. AgLDL-treated macrophages showed an upregulation of $\beta$-catenin, LEF1, c-jun, cyclin D1, bone morphogenetic protein 2 (BMP2) and osteopontin (OPN), proteins and targets of the Wnt signalling pathway, whereas LRP5-silenced macrophages showed a significant down-regulation of OPN and BMP2 expression. In addition, it was observed that LRP5-deficient macrophages exhibited impaired migration [23]. These findings suggest that LRP5 plays a role in the innate inflammatory response to lipid infiltration and thus takes part in the atherosclerotic process.

VSMCs are capable of major phenotypic changes triggered by modifications of local clues including growth factors, mechanical stimuli, cell-cell and cell-matrix interactions and various inflammatory mediators. Migration of VSMCs from the media towards the intima is one of the hallmarks in the development of an atherosclerotic plaque. The activation of VSMCs leads to their proliferation, and migration is accompanied by a switch from a contractile towards a synthetic phenotype, which is characterized by an increased production of cytokines and extracellular matrix [24].

Wnt signaling via $\beta$-catenin is involved in the upregulation of proproliferative genes such as the cyclin D1 gene, which promotes VSMC proliferation [25].

Wnt1, Wnt3a and Wnt4 have been identified to induce activation of canonical Wnt signalling and cyclin D1 expression in VSMCs. On the other hand, the inhibition of Wnt signalling, via the overexpression of sFPR1, a member of the group of secreted frizzled related proteins (sFRP) expressed in the cardiovascular system, resulted in the inhibition of VSMC proliferation both in vitro and in vivo (Table 1) [26-28]. 
Table 1. Implication of Wnt related gene in atherosclerotic process.

\begin{tabular}{|c|c|c|c|c|}
\hline $\begin{array}{l}\text { Wnt Related } \\
\text { Genes }\end{array}$ & Source & Effect & Mechanism & References \\
\hline Wnt1 & ND & VSMCs proliferation & cyclin D expression & {$[27,28]$} \\
\hline Wnt3a & $\begin{array}{c}\text { VSMCs, } \\
\text { Macrophages }\end{array}$ & Anti-inflammatory & suppression of GSK3 $\beta$ & {$[20]$} \\
\hline Wnt4 & ND & VSMCs proliferation & cyclin D1 expression & {$[25,26]$} \\
\hline Wnt5a & Macrophages & $\begin{array}{c}\text { Release of pro-inflammatory } \\
\text { cytokines }\end{array}$ & $\begin{array}{l}\text { Activation of TLR4 } \\
\text { Cyclooxygenase-2 expression }\end{array}$ & {$[16-19,21]$} \\
\hline$D K K-1$ & $\begin{array}{c}\text { Platelets, } \\
\text { endothelial cells }\end{array}$ & $\begin{array}{c}\text { Release of pro-inflammatory } \\
\text { cytokines }\end{array}$ & $\begin{array}{l}\text { platelet-dependent endothelial } \\
\text { activation }\end{array}$ & [22] \\
\hline$s F R P 1$ & $\begin{array}{l}\text { Cardiovascular } \\
\text { system }\end{array}$ & $\begin{array}{l}\text { Inhibition of VSMCs } \\
\text { proliferation }\end{array}$ & Inhibition of Wnt signaling & [27] \\
\hline LRP5 & Macrophages & $\begin{array}{l}\text { OPN and BMP2 expression; } \\
\text { macrophages migration }\end{array}$ & Upregulation of c-jun and cyclin D1 & [23] \\
\hline
\end{tabular}

\section{Sclerostin in Atherosclerosis and Vascular Diseases}

Sclerostin is encoded by the SOST gene, and SOST mRNA expression is detected in a wide number of organs including bone, cartilage, kidney, liver, pancreas, heart and also placenta and fetal skin. However, it has been shown that sclerostin in human subjects is mainly produced by osteocytes and cementocytes, and is identified in serum or plasma, even if, because of technical uncertainties regarding currently available sclerostin assays, circulating sclerostin levels should be interpreted cautiously $[29,30]$.

Although the biological relevance of circulating protein measurements has not been fully elucidated, several clinical studies showed altered sclerostin and DKK-1 concentrations in metabolic bone diseases, in type 1 and 2 diabetes mellitus and in patients with chronic kidney disease (CKD) [31-35].

Interestingly, Pelletier et al. observed that serum sclerostin levels are higher in CKD patients compared with the general population and that they increase with the progression of CKD particularly during, or after, CKD stage III [36]. Thus, sclerostin is inversely correlated with glomerular filtration rate (GFR) [37-39]. The increased sclerostin serum levels observed in CKD could be caused by several factors including sclerostin renal retention, even if it has been reported that urinary sclerostin excretion rises with declining eGFR, but also with an enhanced production by bone cells $[40,41]$.

Recently, SOST expression has been investigated at the vascular level. Particularly, a cross-sectional study involving 46 patients aged 55 to 80 years (mean $71.1 \pm 6.7$ years, 36 men, 15 patients with type 2 diabetes mellitus) explored sclerostin production in atherosclerotic plaques of patients who underwent carotid endarterectomy. Sclerostin was identified in the plaques of all the patients, and its levels were significantly higher in the media compared with the intima, as well as higher in VSMCs compared with infiltrating macrophages, irrespective of history of type 2 diabetes mellitus [42].

Sclerostin has been detected in the aorta of patients undergoing aortic valve replacement and is up-regulated in calcifying VSMCs and calcified valvular plaques [43-46]. It colocalized with vascular calcifications (VCs) of the media and its serum levels were significantly associated with the presence of thoracic aorta calcification (TAC), the severity of TAC and the positive expression of the SOST gene in the vascular system [47].

Furthermore, it should be mentioned that earlier analyses described associations between circulating sclerostin levels with aortic or carotid plaques and VCs, although the direction of association was inconsistent due to methodological issue [35,48-50]. These results were at least partially related to the instrumental detection of calcification, as some studies used vertebral $\mathrm{x}$-ray scans to measure aortic artery calcification $[48,49]$. While this validated method is widely used by studies initially intended for osteoporosis research, it is a semi-quantitative scale with a lower reproducibility than CT-derived calcification measurements as detected through the Agatston method [50,51]. Additionally, previous studies also included different population samples such as diabetic patients, CKD patients or postmenopausal women $[35,49,51]$ (Table 2). 
As for the association with VCs, after adjusting for risk factors including age, physical and lifestyle characteristics, comorbidities, lipoproteins and kidney function, Kuipers et al. found that a sclerostin level greater than $1 \mathrm{SD}$ was associated with a 1.61-times $(95 \% \mathrm{CI} 1.02-2.53)$ greater odds of having aortic artery calcification (CAC). However, sclerostin was not associated with aortic artery calcification (AAC) in any model, suggesting that sclerostin may differentially influence VCs in different vascular beds [50].

How can the correlation between sclerostin and VCs be interpreted? The positive association between serum sclerostin, a Wnt pathway inhibitor, with VCs may seem paradoxical at first sight. Since Wnt signalling is a driver of bone formation and enhances ectopic mineralization, a Wnt inhibitor would be associated with decreased mineralization. Indeed, an antisclerostin antibody treatment increased bone mineralization in humans, and subjects with mutations in the SOST gene showed bone overgrowth and increased mineralization [52-54]. It is noteworthy that sclerostin concentrations have been positively associated both with greater arterial calcification and consistently with greater bone mineral density [50,51].

It could be speculated that augmented serum sclerostin levels may be a physiological adaptation to increased calcification, and could even be a marker of some other mineralization pathway with which the Wnt pathway interacts, such as the nuclear factor kB (RANK)/RANK ligand/osteoprotegerin (OPG) pathway which is also associated with vascular disease in humans $[55,56]$.

Krishna et al. studied the role of SOST in aortic aneurysm (AA) and atherosclerosis using human samples, a mouse model and in vitro experiments. Their research identified that SOST is expressed in the aorta and downregulated in human AA, possibly because of epigenetic silencing. They reported that SOST inhibits angiotensin II (AngII)-induced AA in both the thoracic and abdominal aorta of the mouse model, and also inhibits AngII-induced atherosclerosis. Therefore, upregulation of SOST inhibits AA and atherosclerosis development. These findings suggested a potential implication in the treatment of some vascular diseases [57].

Sclerostin has been proved to be linked with subclinical atherosclerosis. In fact, it was positively or inversely associated with carotid intima-media thickness (CIMT) in postmenopausal women suffering from type 2 diabetes mellitus $[49,58]$.

Looking at patients with CKD, in nondialysis subjects DKK-1, but not sclerostin, was inversely associated with arterial stiffness [58].

Sclerostin serum levels have also been explored in hemodialysis (HD) patients. In a retrospective study, subjects with sclerostin levels above the median value showed a higher prevalence of atherosclerotic plaques $(p=0.025)$ and a higher CIMT $(p=0.038)$. Moreover, at the median follow-up of 61.2 months, high sclerostin baseline levels were evocative of shorter survival predictors of all-cause mortality [59].

Noteworthy, a significant negative association between higher circulating sclerostin levels with mortality was observed in a prospective cohort study of incident dialysis patients $(n=673$, age $63 \pm 14$ yrs.), in the Netherlands. Particularly, after adjustment for various clinical and biochemical parameters, patients in the highest sclerostin tertile had a significantly lower risk of cardiovascular death [hazard ratio $0.29,95 \%$ confidence interval (CI) $0.13-0.62$ ] and for all-cause mortality $(0.39$, 95\% CI 0.22-0.68) within 18 months compared with patients of the lowest tertile. The association of sclerostin levels with outcome was less pronounced for long-term cardiovascular mortality and absent for noncardiovascular mortality [60].

In addition, in a study based on $207 \mathrm{HD}$ patients, subjects in the tertile of higher sclerostin levels, when compared with the tertile of lower sclerostin levels, were significantly older $(73.7 \pm 12$ vs. $64.7 \pm 18$ yrs.), more frequently of the male gender ( $74 \mathrm{vs.} 48 \%$ ), had lower serum bone-specific alkaline phosphatase values ( $14 \pm 9$ vs. $20.4 \pm 13 \mu \mathrm{g} / \mathrm{L}$ ), were less frequently treated with alfacalcidol, displayed lower Kauppila aortic calcification scores (9.5 5 vs. $12.5 \pm 7 / 24)$, had higher bone mineral density (BMD) and showed a lower all-cause mortality rate during a 30-month follow-up period at a multivariable adjusted Cox model (hazard ratio 0.5 , 95\% CI 0.25-0.93, $p=0.03$ ) [61].

However, in a cohort of 165 dialysis patients (mean age $56.5 \pm 15.6$; 84 hemodialysis (HD) and 81 peritoneal dialysis (PD)), during the median follow-up period of 24.9 months, sclerostin level was 
only an independent predictor of all-cause mortality and cardiovascular events (CVEs) in patients with PD after adjusting for confounding factors $(p<0.05)$. Low serum sclerostin was associated with a better overall survival and a lower prevalence of CVEs in patients with PD, but had no relationships in patients with HD [62]. Furthermore, in a predialysis CKD cohort, higher serum sclerostin values were associated, even after multiple adjustments, with fatal and nonfatal CVEs and mortality [63].

Nevertheless, when exploring the effect of sclerostin on CVEs, all-cause/cardiovascular mortality and VCs in patients with CKD, contradictory data exist mainly due to heterogeneity of participants and observation periods. Consequently, in a systematic review and meta-analysis, including nine observational prospective studies involving 1788 patients, an association between sclerostin levels and development of fatal and nonfatal CVEs and all-cause mortality in CKD was not observed [64].

As it is generally known, arterial stiffness describes the rigidity of the arterial wall and is a hallmark of arterial aging [13,48]. In a previous study designed to investigate the relationship between serum levels of sclerostin and DKK-1 with CIMT and arterial stiffness measured by pulse wave velocity (PWV), a predictor of cardiovascular and all-cause mortality, sclerostin, but not DKK-1, emerged as an independent predictor of arterial stiffness in healthy adult outpatient subjects after correcting for confounders [65]. The discrepancy in the behaviour of these two inhibitors of Wnt signalling, which play almost the same role in the vascular cells, has been reported in other studies and may be accounted for by the widespread expression of DKK-1 compared with that of sclerostin $[58,66,67]$.

Sclerostin serum levels were reported to be positively associated with carotid-femoral PWV in several cohorts including women with postmenopausal osteoporosis and patients with CKD $[48,66,67]$.

In a group of $154 \mathrm{HD}$ patients, Jin S. et al. examined the relationship between circulating sclerostin levels and carotid-femoral PWV as a marker of arterial stiffness. They found that serum sclerostin levels were higher in patients with arterial stiffness, but such correlation was lost after adjustments for age, blood pressure, mineral and lipid parameters in a multivariate analysis. However, in a subgroup analysis, according to categories of parathyroid hormone (PTH) serum levels, serum sclerostin level appeared as a significant independent predictor for carotid-femoral PWV in patients with a PTH level under $300 \mathrm{pg} / \mathrm{mL}$, with sclerostin possibly being a suitable biomarker for arterial stiffness [68]. PTH has been observed to inhibit the expression of sclerostin $[69,70]$. Thus, in HD patients with high PTH levels, continuous elevated PTH may suppress the expression of the SOST gene, reducing the secretion of sclerostin and consequently leading to the loss of its hypothetical defensive cardiovascular effect (Figure 2).

Similar to arterial stiffness, VCs are recognized as strong predictors of all-cause and cardiovascular mortality in CKD patients. VCs have been consistently associated with a number of traditional risk factors including age, hypertension and diabetes, as well as with nontraditional risk factors including mineral metabolism disorders [35].

Hampson et al. investigated the association between circulating concentrations of Wnt inhibitors, DKK-1 and sclerostin with bone mineral density (BMD), AAC and arterial stiffness in a cohort of 146 post-menopausal women [48]. AAC, detected by vertebral fracture assessment (VFA) imaging, was quantified using a previously validated 24-point scoring system demonstrating the extension of AAC at the site adjacent to the lumbar vertebrae L1-L4. By dividing the participants into 2 groups based on a PWV cut-off value of $9 \mathrm{~m} / \mathrm{s}$, which was representative of the mean value observed in post-menopausal women, they found that serum sclerostin was significantly higher in women with a PWV $>9 \mathrm{~m} / \mathrm{s}$ compared to women with a PWV $<9 \mathrm{~m} / \mathrm{s}$. After adjustment for age, BMI, smoking habits, blood pressure and lipid levels, a positive association was observed between sclerostin and the AAC score. Differently, DKK-1 showed a negative association with AAC, probably due to a different regulation of its production, not only by osteogenic VSMCs, but also by endothelial cells, platelets or inflammatory cells within the atherosclerotic plaque, which may contribute to circulating DKK-1 concentrations [48]. Therefore, low concentration of DKK-1 could promote mineralization and VCs, whereas high sclerostin levels could attenuate advancing VCs. An equilibrium between these two Wnt inhibitors controls the balance of vascular biology and calcification process. 
Focal intimal calcification of atherosclerotic plaques is a common finding that can affect plaque stability and increase the risk of plaque rupture. Conversely, medial calcification is often widespread and leads to increased arterial stiffness, left ventricular hypertrophy and cardiovascular events. Both forms of arterial intimal and medial calcification of arterial wall enhance mortality risk $[35,48,65]$.

In a cohort of CKD patients undergoing HD, with a median age of 53 years, Pelletier et al. investigated the association between sclerostin and bone status evaluated by high-resolution peripheral quantitative computed tomography (HR-pQCT) at the tibial site, and AAC assessed according to the Kauppila method on lateral spine imaging using dual-energy $x$-ray absorptiometry (DXA). They found that higher sclerostin serum levels and poorer tibia cortical thickness were positively and independently associated with higher odds of severe AAC (Kauppila score of 6 and above). Accordingly, they proposed sclerostin as one of the players involved in the association of mineral and bone disorder with VCs in HD patients [71]. Sclerostin is thus a potential missing link between bone and vascular systems, and participates in the vascular homeostasis.

It has been reported that several drugs may interfere with sclerostin levels mainly related to the treatment of osteoporosis (e.g., antiresorptive and anabolic drugs), but few data are available as to the clinical vascular outcomes and much more focused studies are needed [34,69,70,72-75].

Recently, concerns about cardiovascular safety were raised following the development of a new antiosteoportic treatment based on the monoclonal antibody Romosozumab. It works by inhibiting the activity of sclerostin, leading simultaneously to increased bone formation and, to a lesser extent, decreased bone resorption [76,77]. A recent systematic review and meta-analysis proved that Romosozumab therapy does not increase the risk of composite cardiovascular outcomes (1.26 [95\% CI, 0.95-1.68], $p=0.11$, and three-point major adverse cardiovascular events (1.41 [95\% CI, 0.99-2.02], $p=0.06)$, while it increases the risk of four-point major adverse cardiovascular events $(1.39$ [95\% CI, $1.01-1.90], p=0.04)$ among elderly men and postmenopausal women with osteoporosis over a period of 12-36 months. It has also been highlighted that Romosozumab does not increase or reduce specific cardiovascular outcomes including CV death, myocardial infarction, stroke, atrial fibrillation, heart failure, aortic and intracranial aneurysm, aortic dissection, aortic valve disease and hypertension [78].

In conclusion, several lines of evidence suggest the relevant contribution of sclerostin in the pathophysiology of vascular homeostasis. Sclerostin is a specific and regulated modulator of the Wnt pathway working in several tissues and particularly in bone and vessels. Aging is accompanied by physiological and morphological changes in the cardiovascular system, sometimes reflecting modification of mineral and bone metabolism. Regulators of Wnt signalling, and particularly sclerostin, could become future markers of bone-vessel cross-talk and, possibly, could be included in diagnostic cardiovascular work-up. Drug-induced modulation of sclerostin may even imply subclinical or clinical cardiovascular consequences.

Table 2. Association between sclerostin levels and cardiovascular events.

\begin{tabular}{ccc}
\hline Sclerostin Levels & Cardiovascular Events & References \\
\hline$\uparrow$ & $\downarrow$ CIMT & {$[58]$} \\
\hline$\uparrow$ & $\uparrow$ prevalence of atherosclerotic plaques and $\uparrow$ CIMT & {$[49,59]$} \\
\hline$\uparrow$ & $\uparrow$ PWV & {$[48,65-68]$} \\
\hline$\uparrow$ & $\uparrow$ AAC & {$[48,71]$} \\
\hline$\uparrow$ & $\downarrow$ all-cause mortality and CVEs & {$[60]$} \\
\hline$\uparrow$ & $\uparrow$ AAC; $\uparrow$ all-cause mortality & {$[61]$} \\
\hline$\uparrow$ & $\uparrow$ all-cause mortality and CVEs & {$[62]$} \\
\hline$\uparrow$ & $\uparrow$ fatal and non fatal CVEs & {$[63]$} \\
\hline
\end{tabular}

$\uparrow=$ higher sclerostin levels; $\downarrow=$ lower sclerostin levels; CIMT = carotid intima-media thickness; PWV = pulse wave velocity; CVEs = cardiovascular events; $\mathrm{AAC}=$ aortic artery calcification. 
Author Contributions: Conceptualization: A.C. and F.C.; methodology: A.C., F.B., N.M., F.C.; writing-original draft preparation: A.C., writing-review and editing: A.C., F.B., N.M., F.C.; supervision: N.M. and F.C. All authors have read and agreed to the published version of the manuscript.

Funding: This research received no funding.

Conflicts of Interest: The authors declare no conflict of interest.

\section{Abbreviation List}

\begin{tabular}{|c|c|}
\hline AA & aortic aneurysm \\
\hline AAC & aortic artery calcification \\
\hline agLDL & aggregated LDL \\
\hline AngII & angiotensin II \\
\hline APC & adenomatosis polyposis coli \\
\hline ApoE & apolipoprotein E \\
\hline BMI & body mass index \\
\hline BMD & bone mineral density \\
\hline BMP2 & bone morphogenetic protein 2 \\
\hline $\mathrm{Ca}^{2+}$ & calcium \\
\hline CAC & coronary artery calcification CAC $=$ coronary aortic calcification \\
\hline $\mathrm{CK} 1 \alpha$ & casein kinase $1 \alpha$ \\
\hline CIMT & carotid intima-media thickness \\
\hline CKD & chronic kidney disease \\
\hline CVEs & cardiovascular events \\
\hline DXA & dual-energy x-ray absorptiometry \\
\hline DKK-1 & Dickkopf-related protein 1 \\
\hline Dsh & dishevelled \\
\hline $\mathrm{Fz}$ & frizzled \\
\hline GFR & glomerular filtration rate \\
\hline GSK3 $\beta$ & glycogen synthase kinase $3 \beta$ \\
\hline HD & hemodialysis \\
\hline HR-pQCT & high-resolution peripheral quantitative computed tomography \\
\hline LEF & lymphoid-enhancer binding factor \\
\hline LDL & low-density-lipoprotein \\
\hline LRP5/6 & low-density-lipoprotein-related protein $5 / 6$ \\
\hline LPS & lipopolysaccharide \\
\hline NFKB & nuclear factor $\mathrm{\kappa B}$ \\
\hline OPG & osteoprotegerin \\
\hline OPN & osteopontin \\
\hline PCP & planar cell polarity \\
\hline PD & peritoneal dialysis \\
\hline PPAR $\delta$ & peroxisome proliferator-activated receptor $\delta$ \\
\hline PTH & parathyroid hormone \\
\hline PWV & pulse wave velocity \\
\hline RANK & receptor activator of nuclear factor kappa-B \\
\hline RANKL & receptor activator of nuclear factor kappa-B ligand \\
\hline sFRP & secreted frizzled related proteins \\
\hline TAC & thoracic aorta calcification \\
\hline TCF & $\mathrm{T}$ cell factor \\
\hline TLR4 & toll-like receptor 4 agonist \\
\hline VCs & vascular calcifications \\
\hline VFA & vertebral fracture assessment \\
\hline VSMCs & vascular smooth muscle cells \\
\hline WIF & Wnt inhibitory factor- 1 \\
\hline Wnt & wingless-type MMTV integration site family \\
\hline
\end{tabular}




\section{References}

1. Da Costa, J.P.; Vitorino, R.; Silva, G.M.; Vogel, C.; Duarte, A.C.; Rocha-Santos, T. A synopsis on aging-Theories, mechanisms and future prospects. Ageing Res. Rev. 2006, 29, 90-112. [CrossRef]

2. Ungvari, Z.; Tarantini, S.; Donato, A.J.; Galvan, V.; Csiszar, A. Mechanisms of Vascular Aging. Circ. Res. 2018, 123, 849-867. [CrossRef] [PubMed]

3. López-Otín, C.; Blasco, M.A.; Partridge, L.; Serrano, M.; Kroemer, G. The hallmarks of aging. Cell 2013, 153, 1194-1217. [CrossRef]

4. Kühl, M.; Sheldahl, L.C.; Park, M.; Miller, J.R.; Moon, R.T. The Wnt/Ca2+ pathway: A new vertebrate Wnt signaling pathway takes shape. Trends Genet. 2000, 16, 279-283. [CrossRef]

5. Komiya, Y.; Habas, R. Wnt signal transduction pathways. Organogenesis 2008, 4, 68-75. [CrossRef] [PubMed]

6. Endo, M.; Nishita, M.; Fujii, M.; Minami, Y. Insight into the role of Wnt5a-induced signaling in normal and cancer cells. Int. Rev. Cell Mol. Biol. 2015, 314, 117-148. [CrossRef]

7. Dejana, E. The role of wnt signaling in physiological and pathological angiogenesis. Circ. Res. 2010, 107, 943-952. [CrossRef] [PubMed]

8. Marinou, K.; Christodoulides, C.; Antoniades, C.; Koutsilieris, M. Wnt signaling in cardiovascular physiology. Trends Endocrinol. Metab. 2012, 23, 628-636. [CrossRef]

9. Catalano, A.; Pintaudi, B.; Morabito, N.; Giunta, L.; Loddo, S.; Corrado, F.; D'Anna, R.; Lasco, A.; Di Benedetto, A. Wnt antagonist sclerostin and Dickkopf-1 in gestational diabetes. Diabetes Metab. 2017, 43, 375-377. [CrossRef]

10. Kestler, H.A.; Kühl, M. Generating a Wnt switch: It's all about the right dosage. Int. J. Cell Biol. 2011, 193, 431-433. [CrossRef] [PubMed]

11. Okamoto, M.; Udagawa, N.; Uehara, S.; Maeda, K.; Yamashita, T.; Nakamichi, Y.; Kato, H.; Saito, N.; Minami, Y.; Takahashi, N.; et al. Noncanonical Wnt5a enhances Wnt/ $\beta$-catenin signaling during osteoblastogenesis. Sci. Rep. 2014, 4, 4493. [CrossRef]

12. Libby, P.; Ridker, P.M.; Hansson, G.K. Progress and challenges in translating the biology of atherosclerosis. Nature 2011, 473, 317-325. [CrossRef] [PubMed]

13. Catalano, M.; Lamberti-Castronuovo, A.; Catalano, A.; Filocamo, D.; Zimbalatti, C. Two-dimensional speckle-tracking strain imaging in the assessment of mechanical properties of carotid arteries: Feasibility and comparison with conventional markers of subclinical atherosclerosis. Eur. J. Echocardiogr. 2011, 12, 528-535. [CrossRef] [PubMed]

14. Mani, A.; Radhakrishnan, J.; Wang, H.; Mani, A.; Mani, M.A.; Nelson-Williams, C.; Carew, K.S.; Mane, S.; Najmabadi, H.; Wu, D.; et al. LRP6 mutation in a family with early coronary disease and metabolic risk factors. Science 2007, 315, 1278-1282. [CrossRef]

15. Sarzani, R.; Salvi, F.; Bordicchia, M.; Guerra, F.; Battistoni, I.; Pagliariccio, G.; Carbonari, L.; Dessì-Fulgheri, P.; Rappelli, A. Carotid artery atherosclerosis in hypertensive patients with a functional LDL receptor-related protein 6 gene variant. Nutr. Metab. Cardiovasc. 2011, 21, 150-156. [CrossRef] [PubMed]

16. Christman, M.A.; Goetz, D.J.; Dickerson, E.; McCall, K.D.; Lewis, C.J.; Benencia, F.; Silver, M.J.; Kohn, L.D.; Malgor, R. Wnt5a is expressed in murine and human atherosclerotic lesions. Am. J. Physiol. 2008, 294, H2864-H2870. [CrossRef]

17. Pereira, C.P.; Bachli, E.B.; Schoedon, G. The wnt pathway: A macrophage effector molecule that triggers inflammation. Curr. Atheroscler. Rep. 2009, 11, 236-242. [CrossRef]

18. Bhatt, P.M.; Malgor, R. Wnt5a: A player in the pathogenesis of atherosclerosis and other inflammatory disorders. Atherosclerosis 2014, 237, 155-162. [CrossRef]

19. Blumenthal, A.; Ehlers, S.; Lauber, J.; Buer, J.; Lange, C.; Goldmann, T.; Heine, H.; Brandt, E.; Reiling, N. The Wingless homolog WNT5A and its receptor Frizzled-5 regulate inflammatory responses of human mononuclear cells induced by microbial stimulation. Blood 2006, 108, 965-973. [CrossRef]

20. Schaale, K.; Neumann, J.; Schneider, D.; Ehlers, S.; Reiling, N. Wnt signaling in macrophages: Augmenting and inhibiting mycobacteria-induced inflammatory responses. Eur. J. Cell Biol. 2011, 90, 553-559. [CrossRef]

21. Kim, J.; Kim, J.; Kim, D.W.; Ha, Y.; Ihm, M.H.; Kim, H.; Song, K.; Lee, I. Wnt5a induces endothelial inflammation via beta-catenin-independent signalling. J. Immunol. 2010, 185, 1274-1282. [CrossRef] [PubMed] 
22. Ueland, T.; Otterdal, K.; Lekva, T.; Halvorsen, B.; Gabrielsen, A.; Sandberg, W.J.; Paulsson-Berne, G.; Pedersen, T.M.; Folkersen, L.; Gullestad, L.; et al. Dickkopf-1 enhances inflammatory interaction between platelets and endothelial cells and shows increased expression in atherosclerosis. Arterioscler. Thromb. Vasc. Biol. 2009, 29, 1228-1234. [CrossRef] [PubMed]

23. Borrell-Pagès, M.; Romero, J.C.; Juan-Babot, O.; Badimon, L. Wnt pathway activation, cell migration, and lipid uptake is regulated by low-density lipoprotein receptor-related protein 5 in human macrophages. Eur. Heart J. 2011, 32, 2841-2850. [CrossRef] [PubMed]

24. Owens, G.K.; Kumar, M.S.; Wamhoff, B.R. Molecular regulation of vascular smooth muscle cell differentiation in development and disease. Physiol. Rev. 2004, 84, 767-801. [CrossRef] [PubMed]

25. Quasnichka, H.; Slater, S.C.; Beeching, C.A.; Boehm, M.; Sala-Newby, G.B.; George, S.J. Regulation of smooth muscle cell proliferation by beta-catenin/T-cell factor signaling involves modulation of cyclin D1 and p21 expression. Circ. Res. 2006, 99, 1329-1337. [CrossRef]

26. Marchand, A.; Atassi, F.; Gaaya, A.; Leprince, P.; Le Feuvre, C.; Soubrier, F.; Lompré, A.M.; Nadaud, S. The Wnt/beta-catenin pathway is activated during advanced arterial aging in humans. Aging Cell 2011, 10, 220-232. [CrossRef]

27. Tsaousi, A.; Mill, C.; George, S.J. The Wnt pathways in vascular disease: Lessons from vascular development. Curr. Opin. Lipidol. 2011, 22, 350-357. [CrossRef]

28. Ezan, J.; Leroux, L.; Barandon, L.; Dufourcq, P.; Jaspard, B.; Moreau, C.; Allières, C.; Daret, D.; Couffinhal, T.; Duplàa, C. FrzA/sFRP-1, a secreted antagonist of the Wnt-Frizzled pathway, controls vascular cell proliferation in vitro and in vivo. Cardiovasc. Res. 2004, 63, 731-738. [CrossRef]

29. Balemans, W.; Ebeling, M.; Patel, N.; Van Hul, E.; Olson, P.; Dioszegi, M.; Lacza, C.; Wuyts, W.; Van Den Ende, J.; Willems, P.; et al. Increased bone density in sclerosteosis is due to the deficiency of a novel secreted protein (SOST). Hum. Mol. Genet. 2001, 10, 537-543. [CrossRef]

30. Costa, A.G.; Cremers, S.; Bilezikian, J.P. Sclerostin measurement in human disease: Validity and current limitations. Bone 2017, 96, 24-28. [CrossRef]

31. Gennari, L.; Merlotti, D.; Valenti, R.; Ceccarelli, E.; Ruvio, M.; Pietrini, M.G.; Capodarca, C.; Franci, M.B.; Campagna, M.S.; Calabrò, A.; et al. Circulating sclerostin levels and bone turnover in type 1 and type 2 diabetes. J. Clin. Endocrinol. Metab. 2012, 97, 1737-1744. [CrossRef] [PubMed]

32. Catalano, A.; Pintaudi, B.; Morabito, N.; Di Vieste, G.; Giunta, L.; Bruno, M.L.; Cucinotta, D.; Lasco, A.; Di Benedetto, A. Gender differences in sclerostin and clinical characteristics in type 1 diabetes mellitus. Eur. J. Endocrinol. 2014, 171, 293-300. [CrossRef]

33. Gaudio, A.; Privitera, F.; Battaglia, K.; Torrisi, V.; Sidoti, M.H.; Pulvirenti, I.; Canzonieri, E.; Tringali, G.; Fiore, C.E. Sclerostin levels associated with inhibition of the Wnt/ $\beta$-catenin signaling and reduced bone turnover in type 2 diabetes mellitus. J. Clin. Endocrinol. Metab. 2012, 97, 3744-3750. [CrossRef]

34. Morabito, N.; Catalano, A.; Gaudio, A.; Morini, E.; Bruno, L.M.; Basile, G.; Tsiantouli, E.; Bellone, F.; Agostino, R.M.; Piraino, B.; et al. Effects of strontium ranelate on bone mass and bone turnover in women with thalassemia major-related osteoporosis. J. Bone Miner. Metab. 2016, 34, 540-546. [CrossRef] [PubMed]

35. Claes, K.J.; Viaene, L.; Heye, S.; Meijers, B.; d'Haese, P.; Evenepoel, P. Sclerostin: Another vascular calcification inhibitor? J. Clin. Endocrinol. Metab. 2013, 98, 3221-3228. [CrossRef] [PubMed]

36. Pelletier, S.; Dubourg, L.; Carlier, M.C.; Hadj-Aissa, A.; Fouque, D. The relation between renal function and serum sclerostin in adult patients with CKD. Clin. J. Am. Soc. Nephrol. 2013, 8, 819-823. [CrossRef] [PubMed]

37. Brandenburg, V.M.; D’Haese, P.; Deck, A.; Mekahli, D.; Meijers, B.; Neven, E.; Evenepoel, P. From skeletal to cardiovascular disease in 12 steps-the evolution of sclerostin as a major player in CKD-MBD. Pediatr. Nephrol. 2016, 31, 195-206. [CrossRef] [PubMed]

38. Bonani, M.; Rodriguez, D.; Fehr, T.; Mohebbi, N.; Brockmann, J.; Blum, M.; Graf, N.; Frey, D.; Wüthrich, R.P. Sclerostin blood levels before and after kidney transplantation. Kidney Blood Press. Res. 2014, 39, $230-239$. [CrossRef]

39. Cejka, D.; Marculescu, R.; Kozakowski, N.; Plischke, M.; Reiter, T.; Gessl, A.; Haas, M. Renal elimination of sclerostin increases with declining kidney function. J. Clin. Endocrinol. Metab. 2014, 99, 248-255. [CrossRef]

40. Sabbagh, Y.; Graciolli, F.G.; O’Brien, S.; Tang, W.; dos Reis, L.M.; Ryan, S.; Phillips, L.; Boulanger, J.; Song, W.; Bracken, C.; et al. Repression of osteocyte Wnt/ $\beta$-catenin signaling is an early event in the progression of renal osteodystrophy. J. Bone Miner. Res. 2012, 27, 1757-1772. [CrossRef] 
41. Bruzzese, A.; Lacquaniti, A.; Cernaro, V.; Ricciardi, C.A.; Loddo, S.; Romeo, A.; Montalto, G.; Costantino, G.; Torre, F.; Pettinato, G.; et al. Sclerostin levels in uremic patients: A link between bone and vascular disease. Ren. Fail. 2016, 38, 759-764. [CrossRef] [PubMed]

42. Leto, G.; D’Onofrio, L.; Lucantoni, F.; Zampetti, S.; Campagna, G.; Foffi, C.; Moretti, C.; Carlone, A.; Palermo, A.; Leopizzi, M.; et al. Sclerostin is expressed in the atherosclerotic plaques of patients who undergoing carotid endarterectomy. Diabetes Metab. Res. Rev. 2019, 35, e3069. [CrossRef] [PubMed]

43. Didangelos, A.; Yin, X.; Mandal, K.; Saje, A.; Smith, A.; Xu, Q.; Jahangiri, M.; Mayr, M. Extracellular matrix composition and remodeling in human abdominal aortic aneurysms: A proteomics approach. Mol. Cell. Proteom. 2011, 10. [CrossRef] [PubMed]

44. Zhu, D.; Mackenzie, N.C.; Millán, J.L.; Farquharson, C.; MacRae, V.E. The appearance and modulation of osteocyte marker expression during calcification of vascular smooth muscle cells. PLoS ONE 2011, 6, e19595. [CrossRef]

45. Kramann, R.; Kunter, U.; Brandenburg, V.M.; Leisten, I.; Ehling, J.; Klinkhammer, B.M.; Knüchel, R.; Floege, J.; Schneider, R.K. Osteogenesis of heterotopically transplanted mesenchymal stromal cells in rat models of chronic kidney disease. J. Bone Miner. Res. 2013, 28, 2523-2534. [CrossRef]

46. Koos, R.; Brandenburg, V.; Mahnken, A.H.; Schneider, R.; Dohmen, G.; Autschbach, R.; Marx, N.; Kramann, R. Sclerostin as a potential novel biomarker for aortic valve calcification: An in-vivo and ex-vivo study. J. Heart Valve Dis. 2013, 22, 317-325.

47. Li, M.; Zhou, H.; Yang, M.; Xing, C. Relationship between serum sclerostin, vascular sclerostin expression and vascular calcification assessed by different methods in ESRD patients eligible for renal transplantation: A cross-sectional study. Int. Urol. Nephrol. 2019, 51, 311-323. [CrossRef]

48. Hampson, G.; Edwards, S.; Conroy, S.; Blake, G.M.; Fogelman, I.; Frost, M.L. The relationship between inhibitors of the Wnt signalling pathway (Dickkopf-1(DKK1) and sclerostin), bone mineral density, vascular calcification and arterial stiffness in post-menopausal women. Bone 2013, 56, 42-47. [CrossRef]

49. Morales-Santana, S.; García-Fontana, B.; García-Martín, A.; Rozas-Moreno, P.; García-Salcedo, J.A.; Reyes-García, R.; Muñoz-Torres, M. Atherosclerotic disease in type 2 diabetes is associated with an increase in sclerostin levels. Diabetes Care 2013, 36, 1667-1674. [CrossRef]

50. Kuipers, A.L.; Miljkovic, I.; Carr, J.J.; Terry, J.G.; Nestlerode, C.S.; Ge, Y.; Bunker, C.H.; Patrick, A.L.; Zmuda, J.M. Association of circulating sclerostin with vascular calcification in Afro-Caribbean men. Atherosclerosis 2015, 239, 218-223. [CrossRef]

51. Register, T.C.; Hruska, K.A.; Divers, J.; Bowden, D.W.; Palmer, N.D.; Carr, J.J.; Wagenknecht, L.E.; Hightower, R.C.; $\mathrm{Xu}$, J.; Smith, S.C.; et al. Sclerostin is positively associated with bone mineral density in men and women and negatively associated with carotid calcified atherosclerotic plaque in men from the African American-Diabetes Heart Study. J. Clin. Endocrinol. Metab. 2014, 99, 315-321. [CrossRef] [PubMed]

52. Minisola, S.; Cipriani, C.; Occhiuto, M.; Pepe, J. New anabolic therapies for osteoporosis. Intern. Emerg. Med. 2017, 12, 915-921. [CrossRef]

53. Lewiecki, E.M. New targets for intervention in the treatment of postmenopausal osteoporosis. Nat. Rev. Rheumatol. 2011, 7, 631-638. [CrossRef] [PubMed]

54. Maeda, K.; Kobayashi, Y.; Koide, M.; Uehara, S.; Okamoto, M.; Ishihara, A.; Kayama, T.; Saito, M.; Marumo, K. The Regulation of Bone Metabolism and Disorders by Wnt Signaling. Int. J. Mol. Sci. 2019, 20, 5525. [CrossRef]

55. Frost, M.L.; Grella, R.; Millasseau, S.C.; Jiang, B.Y.; Hampson, G.; Fogelman, I.; Chowienczyk, P.J. Relationship of calcification of atherosclerotic plaque and arterial stiffness to bone mineral density and osteoprotegerin in postmenopausal women referred for osteoporosis screening. Calcif. Tissue Int. 2008, 83, 112-120. [CrossRef] [PubMed]

56. Nybo, M.; Rasmussen, L.M. The capability of plasma osteoprotegerin as a predictor of cardiovascular disease: A systematic literature review. Eur. J. Endocrinol. 2008, 159, 603-608. [CrossRef]

57. Krishna, S.M.; Seto, S.W.; Jose, R.J.; Li, J.; Morton, S.K.; Biros, E.; Wang, Y.; Nsengiyumva, V.; Lindeman, J.H.; Loots, G.G.; et al. Wnt Signaling Pathway Inhibitor Sclerostin Inhibits Angiotensin II-Induced Aortic Aneurysm and Atherosclerosis. Arterioscler. Thromb. Vasc. Biol. 2017, 37, 553-566. [CrossRef]

58. Gaudio, A.; Privitera, F.; Pulvirenti, I.; Canzonieri, E.; Rapisarda, R.; Fiore, C.E. The relationship between inhibitors of the Wnt signalling pathway (sclerostin and Dickkopf-1) and carotid intima-media thickness in postmenopausal women with type 2 diabetes mellitus. Diabetes Vasc. Dis. Res. 2014, 11, 48-52. [CrossRef] 
59. Chen, A.; Sun, Y.; Cui, J.; Zhao, B.; Wang, H.; Chen, X.; Mao, Y. Associations of sclerostin with carotid artery atherosclerosis and all-cause mortality in Chinese patients undergoing maintenance hemodialysis. BMC Nephrol. 2018, 19, 264. [CrossRef]

60. Drechsler, C.; Evenepoel, P.; Vervloet, M.G.; Wanner, C.; Ketteler, M.; Marx, N.; Floege, J.; Dekker, F.W.; Brandenburg, V.M.; NECOSAD Study Group. High levels of circulating sclerostin are associated with better cardiovascular survival in incident dialysis patients: Results from the NECOSAD study. Nephrol. Dial. Transpl. 2015, 30, 288-293. [CrossRef]

61. Jean, G.; Chazot, C.; Bresson, E.; Zaoui, E.; Cavalier, E. High Serum Sclerostin Levels Are Associated with a Better Outcome in Haemodialysis Patients. Nephron 2016, 132, 181-190. [CrossRef] [PubMed]

62. Zou, Y.; Yang, M.; Wang, J.; Cui, L.; Jiang, Z.; Ding, J.; Li, M.; Zhou, H. Association of sclerostin with cardiovascular events and mortality in dialysis patients. Ren. Fail. 2020, 42, 282-288. [CrossRef] [PubMed]

63. Kanbay, M.; Siriopol, D.; Saglam, M.; Kurt, Y.G.; Gok, M.; Cetinkaya, H.; Karaman, M.; Unal, H.U.; Oguz, Y.; Sari, S.; et al. Serum sclerostin and adverse outcomes in nondialyzed chronic kidney disease patients. J. Clin. Endocrinol. Metab. 2014, 99, E1854-E1861. [CrossRef] [PubMed]

64. Kanbay, M.; Solak, Y.; Siriopol, D.; Aslan, G.; Afsar, B.; Yazici, D.; Covic, A. Sclerostin, cardiovascular disease and mortality: A systematic review and meta-analysis. Int. Urol. Nephrol. 2016, 48, 2029-2042. [CrossRef]

65. Gaudio, A.; Fiore, V.; Rapisarda, R.; Sidoti, M.H.; Xourafa, A.; Catalano, A.; Tringali, G.; Zanoli, L.; Signorelli, S.S.; Fiore, C.E. Sclerostin is a possible candidate marker of arterial stiffness: Results from a cohort study in Catania. Mol. Med. Rep. 2017, 15, 3420-3424. [CrossRef]

66. Hsu, B.G.; Liou, H.H.; Lee, C.J.; Chen, Y.C.; Ho, G.J.; Lee, M.C. Serum Sclerostin as an Independent Marker of Peripheral Arterial Stiffness in Renal Transplantation Recipients: A Cross-Sectional Study. Medicine 2016, 95, e3300. [CrossRef]

67. Desjardins, L.; Liabeuf, S.; Oliveira, R.B.; Louvet, L.; Kamel, S.; Lemke, H.D.; Vanholder, R.; Choukroun, G.; Massy, Z.A.; European Uremic Toxin (EUTox) Work Group. Uremic toxicity and sclerostin in chronic kidney disease patients. Nephrol. Ther. 2014, 10, 463-470. [CrossRef]

68. Jin, S.; Zhu, M.; Yan, J.; Fang, Y.; Lu, R.; Zhang, W.; Zhang, Q.; Lu, J.; Qi, C.; Shao, X.; et al. Serum sclerostin level might be a potential biomarker for arterial stiffness in prevalent hemodialysis patients. Biomark. Med. 2016, 10, 689-699. [CrossRef]

69. Piemonte, S.; Romagnoli, E.; Bratengeier, C.; Woloszczuk, W.; Tancredi, A.; Pepe, J.; Cipriani, C.; Minisola, S. Serum sclerostin levels decline in post-menopausal women with osteoporosis following treatment with intermittent parathyroid hormone. J. Endocrinol. Investig. 2012, 35, 866-868. [CrossRef]

70. Catalano, A.; Morabito, N.; Basile, G.; Brancatelli, S.; Cucinotta, D.; Lasco, A. Zoledronic acid acutely increases sclerostin serum levels in women with postmenopausal osteoporosis. J. Clin. Endocrinol. Metab. 2013, 98, 1911-1915. [CrossRef]

71. Pelletier, S.; Confavreux, C.B.; Haesebaert, J.; Guebre-Egziabher, F.; Bacchetta, J.; Carlier, M.C.; Chardon, L.; Laville, M.; Chapurlat, R.; London, G.M.; et al. Serum sclerostin: The missing link in the bone-vessel cross-talk in hemodialysis patients? Osteoporos. Int. 2015, 26, 2165-2174. [CrossRef] [PubMed]

72. Gifre, L.; Ruiz-Gaspà, S.; Monegal, A.; Nomdedeu, B.; Filella, X.; Guañabens, N.; Peris, P. Effect of glucocorticoid treatment on Wnt signalling antagonists (sclerostin and Dkk-1) and their relationship with bone turnover. Bone 2013, 57, 272-276. [CrossRef] [PubMed]

73. Catalano, A.; Loddo, S.; Bellone, F.; Pecora, C.; Lasco, A.; Morabito, N. Pulsed electromagnetic fields modulate bone metabolism via RANKL/OPG and Wnt/ $\beta$-catenin pathways in women with postmenopausal osteoporosis: A pilot study. Bone 2018, 116, 42-46. [CrossRef]

74. Fassio, A.; Adami, G.; Benini, C.; Vantaggiato, E.; Saag, K.G.; Giollo, A.; Lippolis, I.; Viapiana, O.; Idolazzi, L.; Orsolini, G.; et al. Changes in Dkk-1, sclerostin, and RANKL serum levels following discontinuation of long-term denosumab treatment in postmenopausal women. Bone 2019, 123, 191-195. [CrossRef] [PubMed]

75. Gatti, D.; Viapiana, O.; Adami, S.; Idolazzi, L.; Fracassi, E.; Rossini, M. Bisphosphonate treatment of postmenopausal osteoporosis is associated with a dose dependent increase in serum sclerostin. Bone 2012, 50, 739-742. [CrossRef] [PubMed]

76. Cosman, F.; Crittenden, D.B.; Adachi, J.D.; Binkley, N.; Czerwinski, E.; Ferrari, S.; Hofbauer, L.C.; Lau, E.; Lewiecki, E.M.; Miyauchi, A.; et al. Romosozumab Treatment in Postmenopausal Women with Osteoporosis. N. Engl. J. Med. 2016, 375, 1532-1543. [CrossRef] 
77. Khosla, S. Bone diseases: Romosozumab-On track or derailed? Nat. Rev. Endocrinol. 2017, 13, $697-698$. [CrossRef]

78. Lv, F.; Cai, X.; Yang, W.; Gao, L.; Chen, L.; Wu, J.; Ji, L. Denosumab or romosozumab therapy and risk of cardiovascular events in patients with primary osteoporosis: Systematic review and meta-analysis. Bone 2020, 130, 115121. [CrossRef] 